\title{
Vaccines against Human Carcinomas: Strategies to Improve Antitumor Immune Responses
}

\author{
Claudia Palena and Jeffrey Schlom \\ Laboratory of Tumor Immunology and Biology, Center for Cancer Research, National Cancer Institute, \\ National Institutes of Health, Bethesda, MD 20892, USA \\ Correspondence should be addressed to Jeffrey Schlom, js141c@nih.gov
}

Received 7 December 2009; Accepted 8 January 2010

Academic Editor: Zhengguo Xiao

Copyright ( 92010 C. Palena and J. Schlom. This is an open access article distributed under the Creative Commons Attribution License, which permits unrestricted use, distribution, and reproduction in any medium, provided the original work is properly cited.

\begin{abstract}
Multiple observations in preclinical and clinical studies support a role for the immune system in controlling tumor growth and progression. Various components of the innate and adaptive immune response are able to mediate tumor cell destruction; however, certain immune cell populations can also induce a protumor environment that favors tumor growth and the development of metastasis. Moreover, tumor cells themselves are equipped with various mechanisms that allow them to evade surveillance by the immune system. The goal of cancer vaccines is to induce a tumor-specific immune response that ultimately will reduce tumor burden by tipping the balance from a protumor to an antitumor immune environment. This review discusses common mechanisms that govern immune cell activation and tumor immune escape, and some of the current strategies employed in the field of cancer vaccines aimed at enhancing activation of tumor-specific T-cells with concurrent reduction of immunosuppression.
\end{abstract}

\section{Introduction}

The role of the immune system in limiting tumor growth, designated as cancer immunosurveillance [1], has been first elucidated in mouse models of immune deficiency characterized by a high incidence of spontaneous and chemically induced tumors [2]. Those studies have identified several components of the innate and adaptive immune response being responsible for tumor elimination, including $\alpha \beta$ and $\gamma \delta$ T-cells [3], and NK cells [4]. Reinforcing the role of cytotoxic T lymphocytes (CTLs) in the eradication of malignant cells, transgenic mice deficient in perforin, a component of the cytolytic granules of T and NK cells, are more susceptible to spontaneous and chemically induced tumors than their wild type counterparts [5]. In humans, evidence on the role of the immune system in limiting tumor growth and progression is linked to observations indicating a positive correlation between the presence of tumor infiltrating CD8+ T-cells and good prognosis in various types of cancer. In colorectal cancer, for example, significantly higher levels of early memory and effector memory CD8+ T-cell infiltrates positively correlate with good clinical outcome, defined as absence of metastatic invasion, less advanced pathological stage, and increased survival $[6,7]$. Similarly, the presence of intraepithelial tumor infiltrating CD8+ T-cells has been associated with the lack of tumor metastases in the draining lymph nodes of cervical cancer patients [8]. In non-small cell lung carcinoma patients, increasing numbers of tumor infiltrating CD8+, CD20+, and CD4+ T lymphocytes have also been shown to significantly correlate with improved disease-specific survival [9]. Altogether, these observations support a role for the immune system in controlling tumor burden and form the rationale for the development of vaccine-based interventions against cancer that rely on the stimulation of an effective antitumor immune response in the host.

The immune system, however, has two paradoxical roles in cancer. While various components of the innate and adaptive immune response are able to mediate tumor cell destruction, specific types of immune cells can also induce a protumor environment that favors tumor growth and the development of metastasis [10]. Among the latter are, for example, regulatory $\mathrm{T}$ (Treg) cells $[11,12]$, tumor associated macrophages (TAM) $[13,14]$, and type 2 helper CD4+ (Th2) 
T-cells $[15,16]$. These various immune cells have been shown to accumulate at the site of the tumor, negatively impacting the establishment of antitumor T-cell responses, that is, creating an immunosuppressive tumor environment.

Cancer cells themselves are also equipped with mechanisms that allow them to evade recognition by the immune system or to negatively affect the functionality of effector T-cells. In order to avoid immune recognition, tumor cells have been shown to downregulate antigen expression, components of the antigen-processing and presentation machinery, and expression of major histocompatibility complex (MHC) molecules [17]. Decreased expression of costimulatory molecules of crucial importance to T-cell activation, and enhanced surface expression of molecules that negatively regulate activation of T-cells, such as PDL1/B7-H1 and B7-H4, have also been demonstrated in various types of tumors [18-20]. Cancer cells can also restrain the function of the immune system by secreting a milieu of soluble factors that ultimately inhibit the activation, proliferation, and differentiation of the various components of the immune response. Among these molecules are TGF$\beta$ [21], IL-10 [22], IL-13 [23], and VEGF [24].

The goal of vaccine-based cancer immunotherapy approaches is to induce a tumor-specific immune response that ultimately will reduce tumor burden by tipping the balance from a protumor to an antitumor immune environment (Figure 1). This review discusses strategies employed in the field of cancer vaccines aimed at enhancing activation of tumor-specific T-cells with concurrent reduction of immunosuppression. Specifically, vaccine design, immune adjuvants, and multimodal approaches using vaccines in combination with other treatment modalities will be discussed here, with a particular emphasis on studies conducted at the National Cancer Institute, NIH.

\section{Vaccine Design: Choice of Vaccine-Delivery System(s)}

Depending on the vaccine-delivery system of choice, cancer vaccines can elicit an immune response against an individual or multiple tumor antigens. A list of the various types of vaccine-delivery systems under investigation in the field, either at the preclinical or clinical stages, is presented in Table 1. Multiple studies have demonstrated that combinations of some of the strategies in the form of diversified prime/boost regimens may enhance the outcome of the intervention against the tumor [25]. Moreover, it has also been shown that concurrent vaccination with two distinct vaccine platforms targeting the same antigen can elicit a more diverse population of antigen-specific T-cells thus resulting in higher antitumor immunity [26].

Among the various types of vaccine delivery systems, there are strategies based on the use of whole tumor cells, dendritic cells-(DCs-) tumor cell fusions, or preparations of DCs loaded with tumor protein lysates or tumor-derived RNA (Table 1, left column). These vaccine platforms induce an immune response against multiple tumor targets, either known or unknown. Other vaccine modalities (Table 1, right
TABLE 1: Vaccine-delivery systems.

\begin{tabular}{|c|c|}
\hline \multicolumn{2}{|c|}{ Vaccine-delivery systems } \\
\hline $\begin{array}{l}\text { Immunization against multiple } \\
\text { antigens* }\end{array}$ & $\begin{array}{l}\text { Immunization against } \\
\text { specified antigen }(\mathrm{s})\end{array}$ \\
\hline Cell-based & Cell-based \\
\hline Autologous whole-tumor cells & DCs pulsed with peptide \\
\hline Allogeneic whole-tumor cells & Genetically-modified DCs \\
\hline \multicolumn{2}{|l|}{ Genetically-modified tumor cells } \\
\hline DCs-tumor fusion & Protein/Peptide based \\
\hline DCs loaded with tumor lysate & Protein \\
\hline DCs transfected with & Peptide \\
\hline tumor-derived RNA & $\begin{array}{l}\text { Agonist peptide } \\
\text { Antiidiotype } \mathrm{MAb}\end{array}$ \\
\hline Protein/Peptide based & Mab fusion proteins \\
\hline Tumor lysates & Vector-based \\
\hline \multirow[t]{10}{*}{ Heat shock proteins-tumor peptides } & Plasmid DNA \\
\hline & Bacterial vectors \\
\hline & Listeria \\
\hline & Salmonella \\
\hline & Yeast vectors \\
\hline & Viral vectors \\
\hline & Adenovirus \\
\hline & Vaccinia \\
\hline & Avipox (fowlpox) \\
\hline & MVA \\
\hline
\end{tabular}

*Vaccine formulation includes known and unknown antigens.

column) are based on the previous characterization of tumor antigens to be used as "specified" targets in the vaccine formulation.

\section{Tumor Antigens}

Tumor antigens are molecules either exclusively expressed in the tumor cells, designated as "tumor-specific antigens", or molecules that are overexpressed in cancerous versus normal tissues, designated as "tumor-associated antigens". A comprehensive list of tumor antigens and their corresponding Tcell epitopes can be found at $[27,28]$. Table 2 shows a brief list of selected examples for either type of antigen. Tumorspecific antigens appear de novo after cancer cells acquire mutations within the coding regions of certain genes, for example the oncogene ras [29] and the tumor suppressor p53 [30], or novel fusion proteins are generated as in the case of the Bcr-Abl fusion in chronic myeloid leukemia [31]. Moreover, in tumors driven by infectious agents like human papillomavirus (HPV) or Epstein-Barr virus (EBV), virallyderived products become de novo targets of T-cell immune responses directed against the tumor. The majority of tumorassociated antigens so far identified have a certain level of expression in normal tissues and thus tolerance to these antigens often exists. 


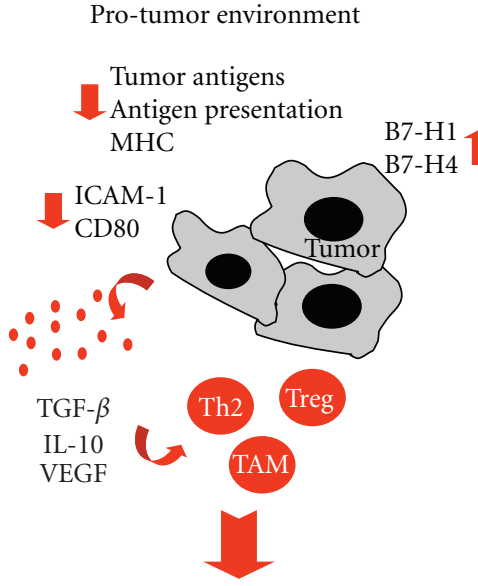

Tumor growth and progression
Anti-tumor immune environment

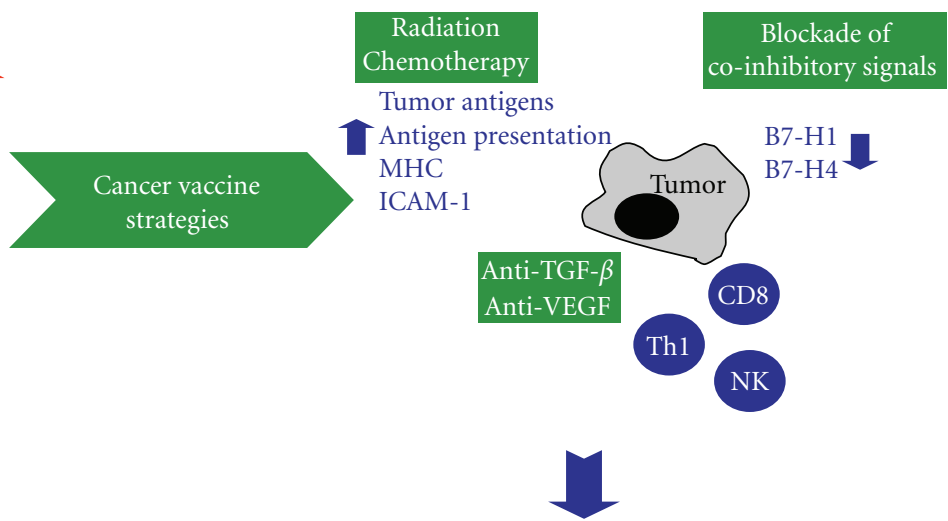

Control of tumor growth and/or progression

Positive clinical outcome

FIGURE 1: Cancer vaccine strategies aimed at shifting the immune environment of a tumor from protumorigenic to antitumorigenic.

A strategy used by tumors to escape immune recognition and destruction is the complete or partial loss of an antigen(s) [17]. Both in experimental animal models $[32,33]$, and in human cancer [34], it has been shown that "antigen-negative tumor variants", characterized by the loss of the targeted antigen, can emerge subsequently to an immune intervention. An approach to overcome this problem is the targeting of "functionally relevant antigens", which are proteins with an essential role during tumor initiation, growth, survival, or metastasis [35]. It can be hypothesized that an immune intervention directed against a functioning tumor antigen would greatly reduce the emergence of antigen-negative variants, since cells that lose the antigen will fail to grow, survive, or metastasize.

\section{Targeting of Molecules that Control Metastatic Dissemination}

In order to achieve the various steps along the metastatic cascade, epithelial tumor cells may need to undergo a phenotypic conversion into mesenchymal cells via a process designated as epithelial-to-mesenchymal transition (EMT) [36]. The EMT program involves the downregulation of epithelial proteins such as E-cadherin and cytokeratins, and the upregulation of mesenchymal proteins including Fibronectin, N-cadherin, and Vimentin. Various genes normally expressed in the early embryo have been implicated in the control of the EMT triggered during tumor progression, including Twist, Snail, Slug, Goosecoid, and SIP1 [36, 37]. The transcription factors encoded by these genes can impart to tumor cells the traits of mesenchymal cells, including motility and the ability to invade the extracellular matrix (ECM). The expression of Twist, for example, has been found to be elevated in various types of cancer, including breast, prostate, and cervical cancer, with higher levels of Twist protein being detected in prostate cancer tissues of high Gleason score $[38,39]$. Since the EMT process
TABLE 2: Human carcinoma antigens.

\begin{tabular}{ll}
\hline \multicolumn{2}{c}{ Carcinoma antigens* } \\
Tumor-specific antigens & Tumor-associated antigens \\
\hline Mutated molecules & Carcinoembryonic antigen (CEA) \\
K-RAS & Mucin 1 (MUC-1) \\
p53 & Prostate-specific antigen (PSA) \\
Fusion molecules & Prostate acid phosphatase (PAP) \\
BCR-ABL & Prostate stem-cell antigen (PSCA) \\
& Brachyury \\
Virally-derived molecules & TERT \\
HPV-16 E6, E7 & Wilm's tumor 1 (WT1) \\
EBNA1, LMP1 and LMP2 & Her-2/neu \\
& Sox-2 \\
& NY-ESO-1 \\
& Cyclin D1 \\
& Mesothelin \\
& Survivin \\
\hline
\end{tabular}

*Included is only a partial list of antigens for human carcinomas.

appears to be a necessary step for tumor cells to initiate the metastatic cascade $[37,40]$, interfering with EMT in early stages of the disease is likely to prevent tumor cell spreading and might also be effective in treating established metastatic lesions (Figure 2). An example of a tumor antigen with a functionally relevant role in the EMT program is the T-box transcription factor Brachyury, highly expressed in various human tumors of epithelial origin, but not in most human normal adult tissues [41]. It has been recently demonstrated that Brachyury overexpression in epithelial tumor cells induces an EMT, promoting the expression of mesenchymal markers and downregulation of epithelial markers, with concomitant increase in tumor cell migration and invasion [42]. Additionally, stable silencing of Brachyury expression in Brachyury-positive human carcinoma cells has been shown to downregulate mesenchymal markers 


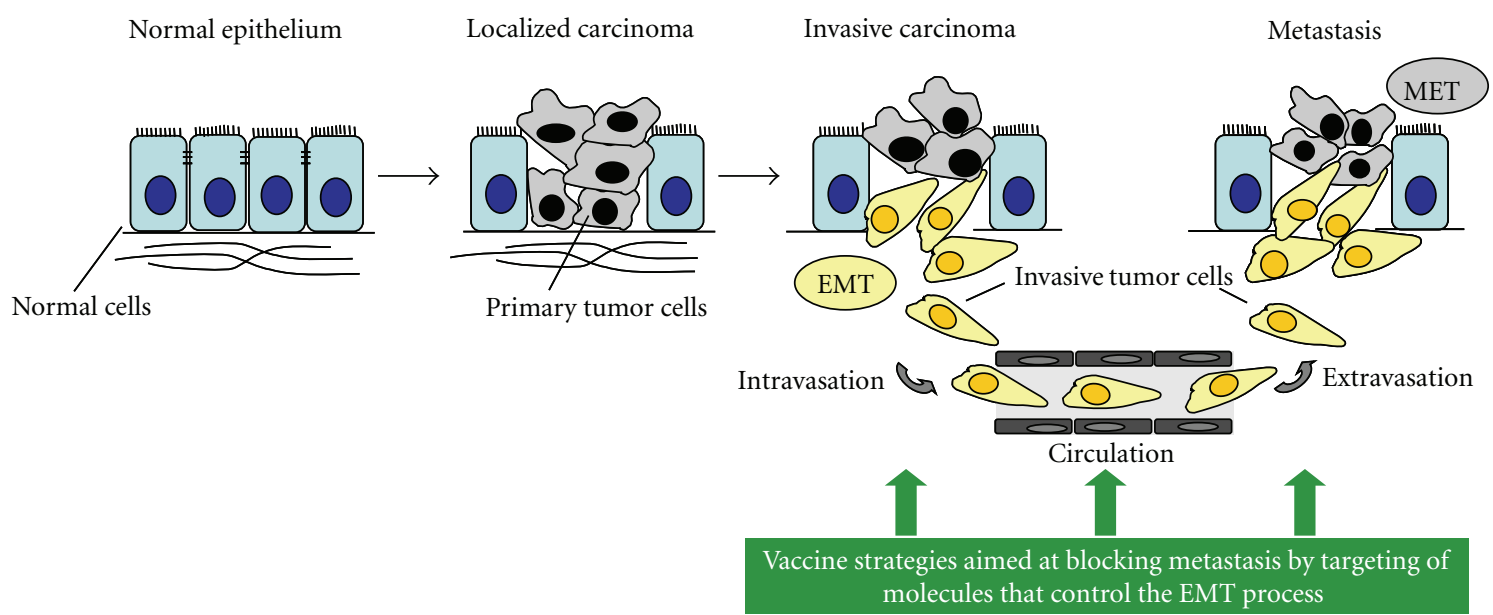

FIGURE 2: The epithelial-to-mesenchymal transition (EMT) in tumor progression: an opportunity to target metastatic tumor cells. The epithelial-to-mesenchymal transition (EMT) and its reverse process, designated as mesenchymal-to-epithelial transition (MET), are involved in the progression of epithelial tumors towards metastasis. Vaccine strategies targeting molecules that control the EMT process, for example, the transcription factor Brachyury, could be used to block tumor spreading.

and upregulate epithelial markers with simultaneous loss of cell migration and ECM invasion. In vivo, Brachyuryinhibited human tumor cells had a decreased ability to form experimental lung metastases after intravenous injection, as well as to disseminate from the primary, subcutaneous tumor to the site of metastases [42]. A CD8 T-cell epitope of Brachyury capable of expanding Brachyury-specific Tcells from the peripheral blood of cancer patients was recently identified [41]; Brachyury-specific T-cells have been used to efficiently lyse Brachyury-positive tumor cells in vitro. The successful expansion of T-cells directed against the transcription factor Brachyury exemplifies the ability of T-cell mediated immunotherapies to target (a) highly conserved tumor proteins, and (b) tumor proteins irrespective of their cellular localization. Because of its relevant role during tumor progression, Brachyury is an appealing tumor antigen for interventions aimed at interfering with the metastatic spreading of tumor cells (Figure 2). Additionally, the transcription factors Twist, Snail, and Slug, among others, which are critically involved in the control of EMT during tumor progression, could also be explored as novel tumor antigens for the targeting of metastatic disease.

\section{Antigen Cascade}

A phenomenon observed with cancer vaccines is the induction of immune responses to tumor antigens that are not present in the vaccine formulation. For example, it has been shown that CEA-transgenic mice cured of CEA-positive tumors by a CEA/TRICOM vaccine regimen were able to subsequently reject CEA-positive as well as CEA-negative tumors, and that this effect was mediated by the generation of specific T-cell immune responses directed against gp70, an antigen expressed by the tumor but not present in the vaccine [43]. The same phenomenon has also been reported in clinical studies [44, 45]. Altogether these studies showed that the immune response initiated against a tumor antigen included in the vaccine formulation is then followed by cross-priming and initiation of an "antigen cascade" that expands the immune response to additional antigens expressed on the tumor, thus potentiating antitumor immunity.

\section{Enhancing Activation of Tumor-Specific T-Cells: The Use of Costimulation in the Vaccine Formulation}

Optimal activation of T-cells is known to require at least two signals. The first signal is mediated by the interaction between the peptide/MHC complex on the surface of antigen presenting cells (APC) and the T-cell receptor (TCR) on the surface of T-cells. The second signal, also designated as costimulation, is mediated by the interaction between accessory molecules located on the surface of the APC and their corresponding ligand(s) on the T-cells [46]. Activation via the TCR in the presence of adequate costimulatory signals results in the clonal expansion, differentiation, and expression of effector functions by antigen-specific T-cells. Optimization of the mechanism of T-cell activation is critical to achieve a successful immune response to an antigen included in a vaccine formulation. A list of various strategies being explored in the field of cancer vaccines to achieve enhanced antitumor immune responses is presented in Table 3. One of them is the delivery of a single or multiple costimulatory molecules along with the tumor antigen as part of the vaccine formulation. One of the most studied Tcell costimulatory molecules is B7-1 $[47,48]$. In preclinical studies it has been shown that mice immunized with an admixture of recombinant vaccinia $(\mathrm{rV}-)$ viruses encoding for a tumor antigen (rV-CEA or rV-MUC-1) and the costimulatory molecule B7-1 (rV-B7-1) generate effective antigen-specific T-cell immune responses that translate into successful antitumor immunity [49]. Furthermore, it was demonstrated that combinations of various costimulatory 
molecules act synergistically to further enhance antigenspecific T-cell responses. Using recombinant vaccinia and fowlpox viruses encoding for the tumor antigen CEA and three different costimulatory molecules (B7-1, ICAM-1, LFA-3, designated as TRICOM), T-cell responses against the tumor antigen were further enhanced above the level observed when only one costimulatory molecule was used [50]. In preclinical studies with human T-cells in vitro, enhanced activation of antigen-specific T-cells was observed against DCs modified by infection with rF-TRICOM [51]. Moreover, the same vector was successfully used to enhance the antigen-presentation potency of freshly isolated B cells, resulting in enhanced activation of antigen-specific T-cell responses in vitro [52]. Results from a Phase II randomized clinical trial in 125 metastatic prostate cancer patients were recently reported [53]; patients were randomized to receive either a vaccine regimen consisting of two recombinant viral vectors each encoding for prostate specific antigen (PSA) and the TRICOM molecules (rV-PSA/TRICOM and rFPSA/TRICOM), or control empty vector (control arm). The results from this trial demonstrated a $44 \%$ reduction in the death rate and an 8.5 month improvement in median overall survival (OS) in men in the vaccine compared to the control arm [53]. Additionally, NCI also reported the results from a randomized Phase II trial in 32 patients with metastatic castrate-resistant prostate cancer, who received a prime with $\mathrm{rV}$-PSA/TRICOM and booster vaccinations with rF-PSA/TRICOM. Twelve of 32 patients showed declines in serum PSA post-vaccination; patients with greater PSAspecific T-cell responses showed a trend toward enhanced survival. In general, there was evidence of enhanced median overall survival, particularly among patients with more indolent type of disease [54]. Overall, cancer vaccine strategies incorporating costimulatory molecules have demonstrated the generation of antitumor immunity and evidence of clinical benefit in cancer patients.

\section{The Use of Cytokines as Vaccine Adjuvants}

7.1. Cytokines that Affect the APCs. Biological adjuvants are agents generally used for improving the immunogenicity of an antigen in a vaccine formulation. Several cytokines have the ability to enhance immune responses by either (a) promoting the differentiation, activation, or recruitment of APC, therefore enhancing antigen presentation and activation of antigen-specific T-cell responses, or (b) by directly acting on various subsets of T-cells. Within the first group, one of the most studied cytokines is the granulocyte-macrophage colony-stimulating factor (GMCSF). It has been demonstrated in preclinical studies that subcutaneous injections of GM-CSF at the vaccination site can significantly increase the infiltration of DCs in regional lymph nodes that drain the site of vaccination $[55,56]$. In several preclinical studies, tumor cells or DCs genetically engineered to secrete biologically active GM-CSF have been used to generate a systemic antitumor immune response $[57,58]$. The use of GM-CSF at high doses, however, could be detrimental in the context of vaccines since it may result
TABLE 3: Strategies to enhance antitumor T-cell responses*.

\begin{tabular}{l}
\hline Strategy \\
\hline Use of costimulation in vaccine formulation \\
Cytokines \\
$\quad$ Effect on APC (GM-CSF) \\
Effect on T-cells (IL-2, IL-7, IL-15, IL-12) \\
Radiation \\
Chemotherapy \\
Small molecule targeted therapies \\
Inhibition of coinhibitory signals \\
$\quad$ At the tumor site (B7-H1, B7-H4) \\
Directly on T-cells (CTLA-4) \\
Depletion/inhibition of Treg cells \\
Inhibition of immunosuppressive cytokines \\
AntiTGF- $\beta$ \\
AntiVEGF
\end{tabular}

* Only a partial list is included here.

in immune suppression via the activation and expansion of myeloid-derived suppressor cells [59]. In the clinical setting, two placebo-controlled Phase III trials in patients with hormone-refractory prostate cancer, for example, have been performed with an autologous DC-based vaccine, designated Sipuleucel- $T$, which is genetically modified to express prostatic acid phosphatase (PAP) as a tumor antigen, and GM-CSF. Results from the initial trial with 127 patients [60] demonstrated a 4.5-month improvement in median survival in the vaccine versus placebo group, though without meeting the primary endpoint of time to progression. Results from a subsequent Phase III, placebo-controlled trial measuring overall survival as the primary endpoint have been recently reported [61], indicating a statistically significant survival advantage in patients in the vaccine versus placebo group.

7.2. Cytokines that Affect the T-Cell Compartment. The second group includes cytokines that directly affect the T-cell compartment by promoting T-cell proliferation, activation, and effector function. Among these, the cytokines IL-2 [62, 63], IL-7 [64], IL-15 [65, 66], and IL-12 [67] are currently under investigation to enhance antitumor immune responses elicited by a vaccine. The most used of these cytokines is IL-2, a T-cell growth factor which, as a single agent, has demonstrated clinical responses in patients with metastatic renal cell carcinoma [68] and metastatic melanoma [69]. A disadvantage, however, in the use of IL-2 therapy in vivo, particularly with high-dose IL-2, is the rate of associated toxicities [70]. Moreover, IL-2 mediates not only the proliferation of activated, effector T-cells and NK cells, but also the development and homeostasis of regulatory T-cells (Tregs), which constitutively express elevated levels of the IL-2R alpha (CD25) [71]. In vitro, IL-2 has also been used to expand tumor-specific T-cells to be used for adoptive immunotherapy [72].

The cytokines IL-15 and IL-7 are also T-cell growth factors; their function, however, is different to that of IL-2 in 
vivo. IL-15 is necessary for the development and homeostasis of memory CD8 T-cells and NK cells [65]. It has also been demonstrated a role for IL-15 in the induction of long-lived, high avidity CD8 T-cells $[73,74]$ and, unlike IL-2, there is no role for IL-15 on the proliferation of Tregs. Up to date, studies with IL-15 as an adjuvant for cancer vaccine strategies have only been conducted in preclinical models, with encouraging results [67]. The cytokine IL-7, another T-cell growth factor, targets a different population of $\mathrm{T}$-cells, promoting the expansion of naïve T-cells and thus increasing the diversity of T-cell repertoire after lymphopenia $[64,65]$. IL-7 has also demonstrated positive results as an adjuvant cytokine for cancer vaccine interventions in preclinical studies [67].

Another cytokine that is under investigation as a vaccine adjuvant is IL-12, which promotes Th1 polarization, proliferation of activated T-cells and NK cells, and cell-mediated immunity. IL-12 has been shown to have potent antitumor effects in preclinical models [75]. In humans, however, the systemic delivery of IL-12 has resulted in elevated toxicities [76], hence leading towards the investigation of alternative modes for local delivery of IL-12. For example, in preclinical studies, a coformulation of IL-12 with chitosan intravesically delivered was well tolerated and very efficient at curing mice with superficial bladder cancer. A durable antitumor immune response was also generated in mice receiving IL-12/chitosan, providing them with complete protection from intravesical tumor rechallenge [77]. Overall, the use of cytokines as vaccine adjuvants to enhance the immune response to a tumor is a very promising and active field of investigation. Current research is focused on understanding the proper ways of delivery for each particular cytokine in order to maximize the immune adjuvant effects while reducing potential toxicities, when used in combination with various types of vaccine platforms.

\section{Vaccine Plus Radiation}

As it was mentioned above, a mechanism by which tumor cells escape immune recognition and attack is through the downregulation of tumor antigens, MHC expression, or various components of the antigen processing/presentation machinery. A strategy to overcome these obstacles is the use of radiation on tumor cells. Radiation is the standard of care for many types of cancer because of its direct cytotoxic effect on the tumor or its palliative effects on the patient. It has been recently reported that local irradiation of tumors with doses insufficient to induce tumor cell death could result in changes on the phenotype of the tumor cells that include the upregulation of MHC, Fas, ICAM-1, and various tumor associated antigens [78-80]. As a result of these changes, irradiated tumor cells are more susceptible to Tcell mediated immune attack. In preclinical studies with a murine colon carcinoma tumor model, sublethal, local tumor irradiation significantly improved the therapeutic efficacy of a recombinant $\mathrm{rV}$-/rF-CEA/TRICOM vaccine regimen against CEA-positive tumors in CEA-transgenic mice [81], while radiation alone or vaccine alone had no effect on tumor growth. In the clinical setting, the approach has been investigated in a phase II clinical trial in patients with localized prostate cancer, randomized to receive a PSAbased poxviral vaccine plus radiotherapy versus radiotherapy alone [82]. The results from this trial indicated increases in PSA-specific T-cell responses of at least 3-fold in patients in the combination arm; the authors also reported evidence of de novo generation of T-cells to well-described prostateassociated antigens not found in the vaccine, providing indirect evidence of immune-mediated tumor killing. These studies thus demonstrated a new paradigm for the use of local tumor irradiation in combination with active vaccine therapy to elicit an effective antitumor immune response.

\section{Vaccines Plus Cytotoxic Drugs}

Because of the widespread use of chemotherapy for the treatment of most malignancies, it is rational to design combinatorial approaches using vaccines plus standard chemotherapeutic agents. Like radiotherapy, the use of various types of chemotherapy in combination with vaccines has resulted in enhanced antitumor immune responses. Although the mechanisms involved vary among the various types of cytotoxic drugs employed, in general, drugs can: (a) induce "immunogenic death" of tumor cells, leading to activation of DCs followed by antigen presentation to Tcells $[83,84]$, or (b) modulate the phenotype of the tumor cells making them more susceptible to immune-mediated killing. For example, it has been shown that treatment of human colon carcinoma cell lines with 5-fluorouracil or cisplatin enhances their lytic sensitivity to antigen-specific CD8+ cytotoxic $\mathrm{T}$ lymphocytes, by inducing expression of ICAM-1 and Fas [85]. Similarly, treatment of renal cell carcinoma cells with subtoxic concentrations of adriamycin has been shown to upregulate the expression of ICAM-1 and LFA-3, as well as to enhance T-cell mediated killing, Fas-mediated, and TRAIL-mediated killing of tumor cells [86]. Taxanes, on the other hand, are a widely used type of chemotherapeutic agents known to have various effects on the immune system, promoting macrophage activation and release of inflammatory cytokines at the tumor site, thus enhancing tumor lysis [87]. In preclinical studies with CEA-transgenic mice transplanted with CEA-positive tumor cells, enhanced antitumor effect was achieved by using a combination of a $\mathrm{rV}-/ \mathrm{rF}-\mathrm{CEA} / \mathrm{TRICOM}$ vaccine regimen plus docetaxel, compared to that of vaccine or docetaxel alone [88]. In preclinical models as well, cyclophosphamide, doxorubicin, and paclitaxel have all been shown to enhance the antitumor immune response elicited with a GM-CSFsecreting, HER2/neu-expressing whole-tumor cell vaccine in tumor bearing neu-transgenic mice [89]. The authors were able to demonstrate that the increased antitumor effects in the combination group (vaccine plus drugs) were due to enhanced vaccine efficacy rather than a direct cytolytic effect of the drugs on cancer cells [89].

Altogether, these studies demonstrated that, if used in appropriate schedule and at the correct doses, chemotherapeutic agents could enhance antitumor responses when used in combination with cancer vaccine modalities. Therefore, 
further studies investigating optimum schedules and dosing for various chemotherapeutic agents are needed in order to optimize the use of different cytotoxic agents in combination with cancer vaccines.

\section{Vaccine Plus Small Molecule Targeted Therapies}

As the molecular pathways involved in the various steps of carcinogenesis and tumor progression are being elucidated with the advent of sophisticated genetic and molecular techniques, a novel group of therapeutic cancer drugs aimed at inhibiting specific molecular pathways is emerging, designated as small molecule targeted therapies. These drugs are also now being investigated for their immune-modulatory functions to be potentially used in combination with cancer vaccines. For example, the anticancer agent lenalidomide (Revlimid, Celgene Corp., NJ, USA), which is FDA approved for the treatment of patients with multiple myeloma, has been shown to have several immune-modulatory effects that include costimulatory effects on CD3-activated T-cells, augmentation of NK cell cytotoxicity, and suppression of Treg cells proliferation and function [90, 91]. Results from a study combining a small molecule BCL-2 inhibitor and a rV/rF-CEA/TRICOM vaccine regimen were recently reported [92]. It has been shown that, when administered after the vaccine, the BCL-2 inhibitor GX15-070 was able to increase the intratumoral ratio of activated, CD8+ T effector to Treg cells, thus resulting in significant reduction of pulmonary tumor nodules in a mouse model of experimental lung tumors [92]. As with chemotherapeutic agents, the use of small molecule targeted therapies could also be associated with potential toxicities and, in particular, with negative effects on the immune compartment. Thus, further studies investigating optimum schedules and dosing for various small molecule targeted drugs are needed in order to optimize their use in combination with cancer vaccines.

\section{Inhibition of Coinhibitory Signals}

An alternative strategy to enhance the outcome of an antitumor immune approach is to eliminate negative signals imparted to T-cells by coinhibitory molecules such as B7H1, B7-H4, and cytotoxic T-lymphocyte antigen-4 (CTLA4 ), among others. B7-H1 is constitutively expressed in many types of human tumors and has been shown to promote evasion of tumor immunity by promoting apoptosis of activated effector T-cells [18] and tumor resistance to Tcell mediated lysis [93]. In preclinical studies, blockade of B7-H1 with a specific monoclonal antibody has resulted in enhanced antitumor immune responses [93, 94]. B7-H4 is another member of the B7 family that has been implicated as a negative regulator of T-cell immunity [95]. It has been demonstrated that $\mathrm{B} 7-\mathrm{H} 4 \mathrm{can}$ inhibit $\mathrm{T}$-cell proliferation and IL-2 production, and that blockade of $\mathrm{B} 7-\mathrm{H} 4$ in preclinical animal models results in enhanced cytotoxic T-cell responses against an alloantigen [19]. The expression of B7-H4 has been observed in many types of human cancer, such as breast
[96], ovary [97], and lung [98]. In renal cell carcinoma, its expression has been correlated with more aggressive tumors, particularly in those cases where both $\mathrm{B} 7-\mathrm{H} 1$ and $\mathrm{B} 7-\mathrm{H} 4$ are aberrantly overexpressed [99]. Therefore, blocking of molecules such as B7-H1 and B7-H4 expressed on tumor cells can reduce coinhibitory signals directly at the site of the tumor (Table 3), resulting in enhanced antitumor immune responses.

A different strategy involves blocking of inhibitory molecules directly expressed on T-cells. An example is CTLA4 , a negative regulator of $\mathrm{T}$-cell activation, which is expressed on the T-cells and, like its homolog CD28, binds to B7 on the surface of the APC. Binding of CTLA- 4 to B7 initiates a negative signal cascade that leads to downregulation of the T-cell response $[100,101]$. The blockade of CTLA- 4 with specific, monoclonal antibodies $(\mathrm{mAb})$ has been explored as a monotherapy or in combination with vaccine therapy in preclinical and clinical studies. In preclinical studies, the use of antiCTLA- $4 \mathrm{mAb}$ as a monotherapy has shown antitumor activity with immunogenic tumors [100, 101], but not with poorly immunogenic tumors, such as MC38 [102]. In combination with vaccines, antiCTLA- $4 \mathrm{mAb}$ has been used to enhance antitumor T-cell responses elicited by the vaccine, thus resulting in effective antitumor effects [102]. In the clinic, antiCTLA- 4 has been used also as a monotherapy or in combination with other immune-mediated anticancer modalities [103]. Results from a phase I clinical trial with antiCTLA-4 mAb (ipilimumab) in patients with metastatic melanoma or renal cell cancer recently reported a $14 \%$ response rate and multiple, and at times severe, immunemediated toxicities such as nephritis, panhypophysitis, and enterocolitis, among others $[104,105]$, this last point constituting a potential disadvantage of the approach.

\section{Depletion/Inhibition of Regulatory T-Cells}

Naturally occurring regulatory $\mathrm{T}$ (Treg) cells, characterized by expression of IL-2R alpha, the transcription factor Foxp3, CTLA-4, and glucocorticoid-induced tumor necrosis factor (TNF) receptor (GITR), constitute $5 \%$ to $10 \%$ of peripheral $\mathrm{CD}^{+}{ }^{+}$T-cells $[11,106]$. Treg cells represent an important mechanism of peripheral T-cell tolerance through their inhibition of self-reactive effector T-cells [107], and have also been implicated in the lack of effective antitumor immunity as the number of Treg cells are increased in the tumors and peripheral blood of cancer patients [108, 109]. Previous studies in several models of mouse tumors have demonstrated that deletion of Treg cells by using an antiCD25 $\mathrm{mAb}$ enhanced the development of antitumor immunity leading to tumor rejection $[110,111]$. Furthermore, it has been previously shown that antigen-specific T-cell responses induced by poxviral vaccines can be augmented by simultaneous administration of antiCD25 mAb in mice [112]. Among alternative modalities that can be used in humans to delete Treg cells is denileukin diftitox, $\left(\mathrm{DAB}_{389} \mathrm{IL}-2\right)$, a fusion protein of IL-2 and diphtheria toxin, previously shown in mouse preclinical studies to reduce Treg cells and to enhance antigen-specific immune responses induced by poxviral 
vaccines [113]. A potential drawback of both approaches is that activated, effector T-cells also transiently upregulate the expression of CD25 on their cell surface, therefore being at risk of depletion by strategies that target CD25. In the clinic, denileukin diftitox was previously shown to reduce Treg cells and to lead to objective clinical responses in patients with ovarian cancer $[12,114]$. Moreover, antitumor immunotherapy approaches combining denileukin diftitoxmediated deletion of Treg cells followed by vaccination with RNA-transfected DCs, tumor antigen peptides, or DCs modified by infection with rF-CEA(6D)/TRICOM, have been shown to improve tumor-specific T-cell responses in patients with renal cell cancer, melanoma, or CEA-positive malignancies, respectively, [115-117].

\section{Inhibition of Immunosuppressive Cytokines}

Tumors can also evade immunosurveillance by directly secreting a number of inhibitory cytokines or by inducing various types of immune cells to secrete cytokines associated with reduced immune responses. One of these cytokines is the transforming growth factor beta (TGF- $\beta$ ), which can be directly secreted by many types of tumor cells, including breast, prostate, colon, liver, lung, and melanomas, among others $[118,119]$. TGF- $\beta$ exerts its negative effects on T-cells, NK cells, macrophages and DCs [120]. Several preclinical studies have demonstrated that blockade of TGF$\beta$ can reverse the immunosuppressive effects of the tumor microenvironment. For example, a small molecule TGF- $\beta$ inhibitor was used in a mouse tumor model to rescue the functionality of infiltrating CD8+ T-cells (TILs), which are usually hyporesponsive [121]. Recently, it was also reported a synergistic improvement of a peptide vaccine modality in combination with a monoclonal antibody against TGF- $\beta$, in a murine tumor model [122]. Although no adverse effects have been observed in studies so far conducted, the dual role of TGF- $\beta$ on normal versus tumor cells, where it can function as a suppressor or promoter of tumor development, respectively, may constitute a potential problem for this approach and indicates the necessity for detailed studies aimed at optimizing the use of antiTGF- $\beta$ reagents while minimizing the potential for adverse effects.

Another cytokine that has a negative impact on the development of antitumor T-cell responses is the vascularendothelial growth factor (VEGF). A major role of VEGF is to induce the process designated as tumor angiogenesis, which involves the development of an adequate tumor vasculature that will support a blood supply to the growing tumor $[123,124]$. Additionally, VEGF contributes to tumor immune escape by inducing the development of immune cell populations with immunosuppressive functions, like immature DCs [24] and the recruitment of tumor-associated macrophages (TAM) to the tumor stroma $[13,14,125]$. Strategies aimed at inhibiting VEGF or its receptors, therefore, will not only disrupt the tumor vasculature thus impairing tumor growth, but will also improve antitumor immunity by eliminating inhibitory cell populations, resulting in enhanced responses to cancer vaccines. In preclinical studies, for example, an antiVEGF antibody enhanced the efficacy of a peptide-pulsed DC-based vaccine that resulted in prolonged and pronounced antitumor effect [126]. Therefore, inhibition of VEGF may be a valuable adjuvant in the immunotherapy of cancer. A disadvantage of antiVEGF therapies in the clinic has been the emergence of toxicities that included wound healing complications as well as adverse vascular effects.

\section{Conclusions}

Progress in understanding the molecular mechanisms that govern immune activation as well as the mechanisms used by tumor cells to evade surveillance by the immune system are advancing the development of immune-mediated therapies that could be effectively used against a range of human cancers. The combination of cancer vaccines with other therapeutical modalities, in particular established therapies such as radiation and chemotherapy, as well as small molecule targeted therapies, provides an opportunity to further improve the outcome of vaccine interventions against cancer. Moreover, several studies also indicated that patients who receive a cancer vaccine have an enhanced outcome to subsequent therapies, thus providing another possible approach for the use of cancer vaccines prior to other cancer interventions. A prospective randomized trial is being initiated to substantiate these findings. Unlike other modalities, cancer vaccines have so far demonstrated no associated toxicities and therefore their use could not only result in improved patient survival but also in improvements in quality of life.

\section{Acknowledgment}

The authors thank Debra Weingarten for editorial assistance in the preparation of this manuscript.

\section{References}

[1] G. P. Dunn, A. T. Bruce, H. Ikeda, L. J. Old, and R. D. Schreiber, "Cancer immunoediting: from immunosurveillance to tumor escape," Nature Immunology, vol. 3, no. 11, pp. 991-998, 2002.

[2] V. Shankaran, H. Ikeda, A. T. Bruce, et al., "IFN $\gamma$, and lymphocytes prevent primary tumour development and shape tumour immunogenicity," Nature, vol. 410, no. 6832, pp. 1107-1111, 2001.

[3] M. Girardi, E. Glusac, R. B. Filler, et al., "The distinct contributions of murine $\mathrm{T}$ cell receptor (TCR) $\gamma \delta+$ and TCR $\alpha \beta+$ T cells to different stages of chemically induced skin cancer," Journal of Experimental Medicine, vol. 198, no. 5, pp. 747-755, 2003.

[4] M. J. Smyth, K. Y. T. Thia, S. E. A. Street, et al., "Differential tumor surveillance by natural killer (NK) and NKT cells," Journal of Experimental Medicine, vol. 191, no. 4, pp. 661$668,2000$.

[5] M. E. van den Broek, D. Kagi, F. Ossendorp, et al., "Decreased tumor surveillance in perforin-deficient mice," Journal of Experimental Medicine, vol. 184, no. 5, pp. 1781-1790, 1996. 
[6] F. Pages, A. Berger, M. Camus, et al., "Effector memory T cells, early metastasis, and survival in colorectal cancer," The New England Journal of Medicine, vol. 353, no. 25, pp. 2654 2666, 2005.

[7] J. Galon, A. Costes, F. Sanchez-Cabo, et al., "Type, density, and location of immune cells within human colorectal tumors predict clinical outcome," Science, vol. 313, no. 5795, pp. 1960-1964, 2006.

[8] S. J. Piersma, E. S. Jordanova, M. I. E. van Poelgeest, et al., "High number of intraepithelial $\mathrm{CD} 8^{+}$tumor-infiltrating lymphocytes is associated with the absence of lymph node metastases in patients with large early-stage cervical cancer," Cancer Research, vol. 67, no. 1, pp. 354-361, 2007.

[9] K. I. Al-Shibli, T. Donnem, S. Al-Saad, M. Persson, R. M. Bremnes, and L.-T. Busund, "Prognostic effect of epithelial and stromal lymphocyte infiltration in non-small cell lung cancer," Clinical Cancer Research, vol. 14, no. 16, pp. 5220 5227, 2008.

[10] D. G. DeNardo, M. Johansson, and L. M. Coussens, "Immune cells as mediators of solid tumor metastasis," Cancer and Metastasis Reviews, vol. 27, no. 1, pp. 11-18, 2008.

[11] T. Yamaguchi and S. Sakaguchi, "Regulatory T cells in immune surveillance and treatment of cancer," Seminars in Cancer Biology, vol. 16, no. 2, pp. 115-123, 2006.

[12] T. J. Curiel, G. Coukos, L. Zou, et al., "Specific recruitment of regulatory $\mathrm{T}$ cells in ovarian carcinoma fosters immune privilege and predicts reduced survival," Nature Medicine, vol. 10, no. 9, pp. 942-949, 2004.

[13] A. Mantovani, S. Sozzani, M. Locati, P. Allavena, and A. Sica, "Macrophage polarization: tumor-associated macrophages as a paradigm for polarized M2 mononuclear phagocytes," Trends in Immunology, vol. 23, no. 11, pp. 549-555, 2002.

[14] Y. Luo, H. Zhou, J. Krueger, et al., "Targeting tumorassociated macrophages as a novel strategy against breast cancer," Journal of Clinical Investigation, vol. 116, no. 8, pp. 2132-2141, 2006.

[15] D. G. DeNardo, J. B. Barreto, P. Andreu, et al., "CD4 ${ }^{+}$T cells regulate pulmonary metastasis of mammary carcinomas by enhancing protumor properties of macrophages," Cancer Cell, vol. 16, no. 2, pp. 91-102, 2009.

[16] A. Ziegler, R. Heidenreich, H. Braumuller, et al., "EpCAM, a human tumor-associated antigen promotes Th2 development and tumor immune evasion," Blood, vol. 113, no. 15, pp. 3494-3502, 2009.

[17] F. M. Marincola, E. M. Jaffee, D. J. Hickljn, and S. Ferrone, "Escape of human solid tumors from t-cell recognition: molecular mechanisms and functional significance," Advances in Immunology, no. 74, pp. 181-273, 2000.

[18] H. Dong, S. E. Strome, D. R. Salomao, et al., "Tumorassociated B7-H1 promotes T-cell apoptosis: a potential mechanism of immune evasion," Nature Medicine, vol. 8, no. 8, pp. 793-800, 2002.

[19] G. L. Sica, I.-H. Choi, G. Zhu, et al., "B7-H4, a molecule of the B7 family, negatively regulates T cell immunity," Immunity, vol. 18, no. 6, pp. 849-861, 2003.

[20] G. Driessens, J. Kline, and T. F. Gajewski, "Costimulatory and coinhibitory receptors in anti-tumor immunity," Immunological Reviews, vol. 229, no. 1, pp. 126-144, 2009.

[21] D. A. Thomas and J. Massague, "TGF- $\beta$ directly targets cytotoxic $\mathrm{T}$ cell functions during tumor evasion of immune surveillance," Cancer Cell, vol. 8, no. 5, pp. 369-380, 2005.

[22] M. Kurte, M. Lopez, A. Aguirre, et al., "A synthetic peptide homologous to functional domain of human IL-10 down-regulates expression of MHC class I and transporter associated with antigen processing $1 / 2$ in human melanoma cells," Journal of Immunology, vol. 173, no. 3, pp. 1731-1737, 2004.

[23] M. Terabe, S. Matsui, N. Noben-Trauth, et al., "NKT cellmediated repression of tumor immunosurveillance by IL-13 and the IL-4R-STAT6 pathway," Nature Immunology, vol. 1, no. 6, pp. 515-520, 2000.

[24] D. I. Gabrilovich, H. L. Chen, K. R. Girgis, et al., "Production of vascular endothelial growth factor by human tumors inhibits the functional maturation of dendritic cells," Nature Medicine, vol. 2, no. 10, pp. 1096-1103, 1996.

[25] J. L. Marshall, R. J. Hoyer, M. A. Toomey, et al., "Phase I study in advanced cancer patients of a diversified primeand-boost vaccination protocol using recombinant vaccinia virus and recombinant nonreplicating avipox virus to elicit anti-carcinoembryonic antigen immune responses," Journal of Clinical Oncology, vol. 18, no. 23, pp. 3964-3973, 2000.

[26] A. L. Boehm, J. Higgins, A. Franzusoff, J. Schlom, and J. W. Hodge, "Concurrent vaccination with two distinct vaccine platforms targeting the same antigen generates phenotypically and functionally distinct T-cell populations," Cancer Immunology, Immunotherapy, vol. 59, no. 3, pp. 397408, 2010.

[27] M. A. Cheever, J. P. Allison, A. S. Ferris, et al., "The prioritization of cancer antigens: a National Cancer Institute pilot project for the acceleration of translational research," Clinical Cancer Research, vol. 15, no. 17, pp. 5323-5337, 2009.

[28] P. van der Bruggen, V. Stroobant, A. van Pel, and B. van den Eynde, "T-cell defined tumor antigens," http://www.cancerimmunity.org/peptidedatabase/ Tcellepitopes.htm.

[29] S. I. Abrams, S. F. Stanziale, S. D. Lunin, S. Zaremba, and J. Schlom, "Identification of overlapping epitopes in mutant ras oncogene peptides that activate $\mathrm{CD}^{+}$and $\mathrm{CD} 8^{+} \mathrm{T}$ cell responses," European Journal of Immunology, vol. 26, no. 2, pp. 435-443, 1996.

[30] R. Offringa, M. P. M. Vierboom, S. H. van der Burg, L. Erdile, and C. J. M. Melief, "p53: a potential target antigen for immunotherapy of cancer," Annals of the New York Academy of Sciences, vol. 910, pp. 223-236, 2000.

[31] J. H. Kessler, S. A. Bres-Vloemans, P. A. van Veelen, et al., "BCR-ABL fusion regions as a source of multiple leukemiaspecific CD8 ${ }^{+}$T-cell epitopes," Leukemia, vol. 20, no. 10, pp. 1738-1750, 2006.

[32] K. L. Knutson, H. Lu, B. Stone, et al., "Immunoediting of cancers may lead to epithelial to mesenchymal transition," Journal of Immunology, vol. 177, no. 3, pp. 1526-1533, 2006.

[33] M. Kmieciak, K. L. Knutson, C. I. Dumur, and M. H. Manjili, "HER-2/neu antigen loss and relapse of mammary carcinoma are actively induced by $\mathrm{T}$ cell-mediated anti-tumor immune responses," European Journal of Immunology, vol. 37, no. 3, pp. 675-685, 2007.

[34] E. Jager, M. Ringhoffer, J. Karbach, M. Arand, F. Oesch, and A. Knuth, "Inverse relationship of melanocyte differentiation antigen expression in melanoma tissues and CD8 ${ }^{+}$cytotoxicT-cell responses: evidence for immunoselection of antigenloss variants in vivo," International Journal of Cancer, vol. 66, no. 4, pp. 470-476, 1996.

[35] Y. Hirohashi, T. Torigoe, S. Inoda, et al., "The functioning antigens: beyond just as the immunological targets," Cancer Science, vol. 100, no. 5, pp. 798-806, 2009.

[36] J. P. Thiery and J. P. Sleeman, "Complex networks orchestrate epithelial-mesenchymal transitions," Nature Reviews Molecular Cell Biology, vol. 7, no. 2, pp. 131-142, 2006. 
[37] J. P. Thiery, "Epithelial-mesenchymal transitions in tumour progression," Nature Reviews Cancer, vol. 2, no. 6, pp. 442 454, 2002.

[38] J. Yang, S. A. Mani, J. L. Donaher, et al., “Twist, a master regulator of morphogenesis, plays an essential role in tumor metastasis," Cell, vol. 117, no. 7, pp. 927-939, 2004.

[39] W. K. Kwok, M.-T. Ling, T.-W. Lee, et al., "Up-regulation of TWIST in prostate cancer and its implication as a therapeutic target," Cancer Research, vol. 65, no. 12, pp. 5153-5162, 2005.

[40] R. Kalluri and R. A. Weinberg, "The basics of epithelialmesenchymal transition," Journal of Clinical Investigation, vol. 119, no. 6, pp. 1420-1428, 2009.

[41] C. Palena, D. E. Polev, K. Y. Tsang, et al., "The human T-box mesodermal transcription factor Brachyury is a candidate target for T-cell - mediated cancer immunotherapy," Clinical Cancer Research, vol. 13, no. 8, pp. 2471-2478, 2007.

[42] R. I. Fernando, M. Litzinger, P. Trono, D. H. Hamilton, J. Schlom, and C. Palena, "The T-box transcription factor Brachyury promotes epithelial-mesenchymal transition in human tumor cells," Journal of Clinical Investigation, vol. 120, no. 2, pp. 533-544, 2010.

[43] C. Kudo-Saito, J. Schlom, and J. W. Hodge, "Induction of an antigen cascade by diversified subcutaneous/intratumoral vaccination is associated with antitumor responses," Clinical Cancer Research, vol. 11, no. 6, pp. 2416-2426, 2005.

[44] L. H. Butterfield, A. Ribas, V. B. Dissette, et al., "Determinant spreading associated with clinical response in dendritic cellbased immunotherapy for malignant melanoma," Clinical Cancer Research, vol. 9, no. 3, pp. 998-1008, 2003.

[45] P. M. Arlen, J. L. Gulley, C. Parker, et al., "A randomized phase II study of concurrent docetaxel plus vaccine versus vaccine alone in metastatic androgen-independent prostate cancer," Clinical Cancer Research, vol. 12, no. 4, pp. 1260-1269, 2006.

[46] R. H. Schwartz, "A cell culture model for T lymphocyte clonal anergy," Science, vol. 248, no. 4961, pp. 1349-1356, 1990.

[47] F. A. Harding, J. G. McArthur, J. A. Gross, D. H. Raulet, and J. P. Allison, "CD28-mediated signalling co-stimulates murine $\mathrm{T}$ cells and prevents induction of anergy in T-cell clones," Nature, vol. 356, no. 6370, pp. 607-609, 1992.

[48] X. Zang and J. P. Allison, "The B7 family and cancer therapy: costimulation and coinhibition," Clinical Cancer Research, vol. 13, no. 18, part 1, pp. 5271-5279, 2007.

[49] J. W. Hodge, J. P. McLaughlin, S. I. Abrams, W. L. Shupert, J. Schlom, and J. A. Kantor, "Admixture of a recombinant vaccinia virus containing the gene for the costimulatory molecule B7 and a recombinant vaccinia virus containing a tumor-associated antigen gene results in enhanced specific T-Cell responses and antitumor immunity," Cancer Research, vol. 55, no. 16, pp. 3598-3603, 1995.

[50] J. W. Hodge, H. Sabzevari, A. G. Yafal, L. Gritz, M. G. O. Lorenz, and J. Schlom, "A triad of costimulatory molecules synergize to amplify T-cell activation," Cancer Research, vol. 59, no. 22, pp. 5800-5807, 1999.

[51] M. Zhu, H. Terasawa, J. Gulley, et al., "Enhanced activation of human T cells via avipox vector-mediated hyperexpression of a triad of costimulatory molecules in human dendritic cells," Cancer Research, vol. 61, no. 9, pp. 3725-3734, 2001.

[52] C. Palena, M. Zhu, J. Schlom, and K.-Y. Tsang, "Human B cells that hyperexpress a triad of costimulatory molecules via avipox-vector infection: an alternative source of efficient antigen-presenting cells," Blood, vol. 104, no. 1, pp. 192-199, 2004.

[53] P. W. Kantoff, T. J. Schuetz, B. A. Blumenstein, et al., "Overall survival (OS) analysis of a phase II randomized controlled trial (RCT) of a poxviral-based PSA targeted immunotherapy in metastatic castration-resistant prostate cancer (mCRPC)," Journal of Clinical Oncology, vol. 28, no. 7, pp. 1099-1105, 2010.

[54] J. L. Gulley, P. M. Arlen, R. A. Madan, et al., "Immunologic and prognostic factors associated with overall survival employing a poxviral-based PSA vaccine in metastatic castrate-resistant prostate cancer," Cancer Immunology, Immunotherapy, vol. 59, no. 5, pp. 663-674, 2010.

[55] E. Kass, D. L. Panicali, G. Mazzara, J. Seldom, and J. W. Greiner, "Granulocyte/macrophage-colony stimulating factor produced by recombinant avian poxviruses enriches the regional lymph nodes with antigen-presenting cells and acts as an immunoadjuvant," Cancer Research, vol. 61, no. 1, pp. 206-214, 2001.

[56] E. Kass, J. Parker, J. Schlom, and J. W. Greiner, "Comparative studies of the effects of recombinant GM-CSF and GM-CSF administered via a poxvirus to enhance the concentration of antigen- presenting cells in regional lymph nodes," Cytokine, vol. 12, no. 7, pp. 960-971, 2000.

[57] G. Dranoff, E. Jaffee, A. Lazenby, et al., "Vaccination with irradiated tumor cells engineered to secrete murine granulocyte-macrophage colony-stimulating factor stimulates potent, specific, and long-lasting anti-tumor immunity," Proceedings of the National Academy of Sciences of the United States of America, vol. 90, no. 8, pp. 3539-3543, 1993.

[58] G. Dranoff, "GM-CSF-secreting melanoma vaccines," Oncogene, vol. 22, no. 20, pp. 3188-3192, 2003.

[59] G. Parmiani, C. Castelli, L. Pilla, M. Santinami, M. P. Colombo, and L. Rivoltini, "Opposite immune functions of GM-CSF administered as vaccine adjuvant in cancer patients," Annals of Oncology, vol. 18, no. 2, pp. 226-232, 2007.

[60] E. J. Small, P. F. Schellhammer, C. S. Higano, et al., "Placebo-controlled phase III trial of immunologic therapy with Sipuleucel-T (APC8015) in patients with metastatic, asymptomatic hormone refractory prostate cancer," Journal of Clinical Oncology, vol. 24, no. 19, pp. 3089-3094, 2006.

[61] P. Schellhammer, C. Higano, E. Berger, et al., "A randomized, double-blind, placebo-controlled multi-center, phase III trial of sipuleucel-T in men with metastatic, androgen independent prostatic adenocarcinoma (AIPC)," in Proceedings of the American Urological Association Annual Meeting, Chicago, Ill, USA, April 2009.

[62] F. O. Smith, S. G. Downey, J. A. Klapper, et al., "Treatment of metastatic melanoma using Interleukin-2 alone or in conjunction with vaccines," Clinical Cancer Research, vol. 14, no. 17 , pp. 5610-5618, 2008.

[63] B. Heemskerk, K. Liu, M. E. Dudley, et al., "Adoptive cell therapy for patients with melanoma, using tumor-infiltrating lymphocytes genetically engineered to secrete interleukin-2," Human Gene Therapy, vol. 19, no. 5, pp. 496-510, 2008.

[64] F. Melchionda, T. J. Fry, M. J. Milliron, M. A. McKirdy, Y. Tagaya, and C. L. Mackall, "Adjuvant IL-7 or IL-15 overcomes immunodominance and improves survival of the $\mathrm{CD}^{+}$ memory cell pool," Journal of Clinical Investigation, vol. 115, no. 5, pp. 1177-1187, 2005.

[65] T. A. Waldmann, "The biology of interleukin-2 and interleukin-15: implications for cancer therapy and vaccine design," Nature Reviews Immunology, vol. 6, no. 8, pp. 595601, 2006.

[66] N. Sato, H. J. Patel, T. A. Waldmann, and Y. Tagaya, "The IL$15 / \mathrm{IL}-15 \mathrm{R} \alpha$ on cell surfaces enables sustained IL-15 activity and contributes to the long survival of CD8 memory T cells," 
Proceedings of the National Academy of Sciences of the United States of America, vol. 104, no. 2, pp. 588-593, 2007.

[67] M. A. Cheever, "Twelve immunotherapy drugs that could cure cancers," Immunological Reviews, vol. 222, no. 1, pp. 357-368, 2008.

[68] D. F. McDermott and M. B. Atkins, "Immunotherapy of metastatic renal cell carcinoma," Cancer Journal, vol. 14, no. 5, pp. 320-324, 2008.

[69] T. Petrella, I. Quirt, S. Verma, A. E. Haynes, M. Charette, and K. Bak, "Single-agent interleukin-2 in the treatment of metastatic melanoma: a systematic review," Cancer Treatment Reviews, vol. 33, no. 5, pp. 484-496, 2007.

[70] M. Rosenstein, S. E. Ettinghausen, and S. A. Rosenberg, "Extravasation of intravascular fluid mediated by the systemic administration of recombinant interleukin 2," Journal of Immunology, vol. 137, no. 5, pp. 1735-1742, 1986.

[71] M. Ahmadzadeh and S. A. Rosenberg, "IL-2 administration increases $\mathrm{CD}^{+} \mathrm{CD} 25 \mathrm{hi} \mathrm{Foxp}^{+}$regulatory $\mathrm{T}$ cells in cancer patients," Blood, vol. 107, no. 6, pp. 2409-2414, 2006.

[72] M. E. Dudley, J. R. Wunderlich, T. E. Shelton, J. Even, and S. A. Rosenberg, "Generation of tumor-infiltrating lymphocyte cultures for use in adoptive transfer therapy for melanoma patients," Journal of Immunotherapy, vol. 26, no. 4, pp. 332 342, 2003.

[73] F. Villinger, R. Miller, K. Mori, et al., "IL-15 is superior to IL-2 in the generation of long-lived antigen specific memory CD4 and CD8 T cells in rhesus macaques," Vaccine, vol. 22, no. 25-26, pp. 3510-3521, 2004.

[74] M. A. Kutzler, T. M. Robinson, M. A. Chattergoon, et al., "Coimmunization with an optimized IL-15 plasmid results in enhanced function and longevity of CD8 T cells that are partially independent of CD4 T cell help," Journal of Immunology, vol. 175, no. 1, pp. 112-123, 2005.

[75] M. P. Colombo and G. Trinchieri, "Interleukin-12 in antitumor immunity and immunotherapy," Cytokine and Growth Factor Reviews, vol. 13, no. 2, pp. 155-168, 2002.

[76] J. P. Leonard, M. L. Sherman, G. L. Fisher, et al., "Effects of single-dose interleukin-12 exposure on interleukin-12 associated toxicity and interferon- $\gamma$ production," Blood, vol. 90, no. 7, pp. 2541-2548, 1997.

[77] D. A. Zaharoff, B. S. Hoffman, H. B. Hooper, et al., "Intravesical immunotherapy of superficial bladder cancer with chitosan/interleukin-12," Cancer Research, vol. 69, no. 15, pp. 6192-6199, 2009.

[78] M. Chakraborty, S. I. Abrams, K. Camphausen, et al., "Irradiation of tumor cells up-regulates Fas and enhances CTL lytic activity and CTL adoptive immunotherapy," Journal of Immunology, vol. 170, no. 12, pp. 6338-6347, 2003.

[79] C. T. Garnett, C. Palena, M. Chakarborty, K.-Y. Tsang, J. Schlom, and J. W. Hodge, "Sublethal irradiation of human tumor cells modulates phenotype resulting in enhanced killing by cytotoxic T lymphocytes," Cancer Research, vol. 64, no. 21, pp. 7985-7994, 2004.

[80] E. A. Reits, J. W. Hodge, C. A. Herberts, et al., "Radiation modulates the peptide repertoire, enhances MHC class I expression, and induces successful antitumor immunotherapy," Journal of Experimental Medicine, vol. 203, no. 5, pp. 1259-1271, 2006.

[81] M. Chakraborty, S. I. Abrams, C. N. Coleman, K. Camphausen, J. Schlom, and J. W. Hodge, "External beam radiation of tumors alters phenotype of tumor cells to render them susceptible to vaccine-mediated T-cell killing," Cancer Research, vol. 64, no. 12, pp. 4328-4337, 2004.
[82] J. L. Gulley, P. M. Arlen, A. Bastian, et al., "Combining a recombinant cancer vaccine with standard definitive radiotherapy in patients with localized prostate cancer," Clinical Cancer Research, vol. 11, no. 9, pp. 3353-3362, 2005.

[83] R. A. Lake and R. G. van der Most, "A better way for a cancer cell to die," The New England Journal of Medicine, vol. 354, no. 23, pp. 2503-2504, 2006.

[84] A. Tesniere, F. Schlemmer, V. Boige, et al., "Immunogenic death of colon cancer cells treated with oxaliplatin," Oncogene, vol. 29, no. 4, pp. 482-491, 2010.

[85] E. S. Bergmann-Leitner and S. I. Abrams, "Treatment of human colon carcinoma cell lines with anti-neoplastic agents enhances their lytic sensitivity to antigen-specific $\mathrm{CD} 8^{+}$cytotoxic T lymphocytes," Cancer Immunology, Immunotherapy, vol. 50, no. 9, pp. 445-455, 2001.

[86] X. X. Wu, Y. Zeng, X. H. Jin, and Y. Kakehi, "Enhanced susceptibility of adriamycin-treated human renal cell carcinoma cells to lysis by peripheral blood lymphocytes and tumor infiltrating lymphocytes," Oncology Reports, vol. 18, no. 2, pp. 353-359, 2007.

[87] O. T. M. Chan and L.-X. Yang, "The immunological effects of taxanes," Cancer Immunology, Immunotherapy, vol. 49, no. 4-5, pp. 181-185, 2000.

[88] C. T. Garnett, J. Schlom, and J. W. Hodge, "Combination of docetaxel and recombinant vaccine enhances T-cell responses and antitumor activity: effects of docetaxel on immune enhancement," Clinical Cancer Research, vol. 14, no. 11, pp. 3536-3544, 2008.

[89] J.-P. H. Machiels, R. T. Reilly, L. A. Emens, et al., "Cyclophosphamide, doxorubicin, and paclitaxel enhance the antitumor immune response of granulocyte/macrophage-colony stimulating factor-secreting whole-cell vaccines in HER-2/neu tolerized mice," Cancer Research, vol. 61, no. 9, pp. 36893697, 2001.

[90] C. Galustian, M.-C. Labarthe, J. B. Bartlett, and A. G. Dalgleish, "Thalidomide-derived immunomodulatory drugs as therapeutic agents," Expert Opinion on Biological Therapy, vol. 4, no. 12, pp. 1963-1970, 2004.

[91] C. Galustian, B. Meyer, M.-C. Labarthe, et al., "The anticancer agents lenalidomide and pomalidomide inhibit the proliferation and function of $\mathrm{T}$ regulatory cells," Cancer Immunology, Immunotherapy, vol. 58, no. 7, pp. 1033-1045, 2009.

[92] B. Farsaci, H. Sabzevari, M. G. Di Bari, S. Takai, J. Schlom, and J. W. Hodge, "Effect of a small molecule BCL-2 inhibitor on immune function and use with a recombinant vaccine," International Journal of Cancer, 2010 Jan 20. [Epub ahead of print].

[93] Y. Iwai, M. Ishida, Y. Tanaka, T. Okazaki, T. Honjo, and N. Minato, "Involvement of PD-L1 on tumor cells in the escape from host immune system and tumor immunotherapy by PD-L1 blockade," Proceedings of the National Academy of Sciences of the United States of America, vol. 99, no. 19, pp. 12293-12297, 2002.

[94] F. Hirano, K. Kaneko, H. Tamura, et al., "Blockade of B7$\mathrm{H} 1$ and PD-1 by monoclonal antibodies potentiates cancer therapeutic immunity," Cancer Research, vol. 65, no. 3, pp. 1089-1096, 2005.

[95] D. V. R. Prasad, S. Richards, X. M. Mai, and C. Dong, “ B7S1, a novel B7 family member that negatively regulates $\mathrm{T}$ cell activation," Immunity, vol. 18, no. 6, pp. 863-873, 2003.

[96] B. Tringler, S. Zhuo, G. Pilkington, et al., "B7-H4 is highly expressed in ductal and lobular breast cancer," Clinical Cancer Research, vol. 11, no. 5, pp. 1842-1848, 2005. 
[97] B. Tringler, W. Liu, L. Corral, et al., "B7-H4 overexpression in ovarian tumors," Gynecologic Oncology, vol. 100, no. 1, pp. 44-52, 2006.

[98] Y. Sun, Y. Wang, J. Zhao, et al., "B7-H3 and B7-H4 expression in non-small-cell lung cancer," Lung Cancer, vol. 53, no. 2, pp. 143-151, 2006.

[99] A. E. Krambeck, R. H. Thompson, H. Dong, et al., "B7-H4 expression in renal cell carcinoma and tumor vasculature: associations with cancer progression and survival," Proceedings of the National Academy of Sciences of the United States of America, vol. 103, no. 27, pp. 10391-10396, 2006.

[100] J. G. Egen and J. P. Allison, "Cytotoxic T lymphocyte antigen4 accumulation in the immunological synapse is regulated by TCR signal strength," Immunity, vol. 16, no. 1, pp. 23-35, 2002.

[101] J. G. Egen, M. S. Kuhns, and J. P. Allison, "CTLA-4: new insights into its biological function and use in tumor immunotherapy," Nature Immunology, vol. 3, no. 7, pp. 611618, 2002.

[102] J. W. Hodge, M. Chakraborty, C. Kudo-Saito, C. T. Garnett, and J. Schlom, "Multiple costimulatory modalities enhance CTL avidity," Journal of Immunology, vol. 174, no. 10, pp. 5994-6004, 2005.

[103] A. A. Sarnaik and J. S. Weber, "Recent advances using antiCTLA-4 for the treatment of melanoma," Cancer Journal, vol. 15, no. 3, pp. 169-173, 2009.

[104] K. E. Beck, J. A. Blansfield, K. Q. Tran, et al., "Enterocolitis in patients with cancer after antibody blockade of cytotoxic Tlymphocyte-associated antigen 4," Journal of Clinical Oncology, vol. 24, no. 15, pp. 2283-2289, 2006.

[105] J. A. Blansfield, K. E. Beck, K. Tran, et al., "Cytotoxic T-lymphocyte-associated antigen-4 blockage can induce autoimmune hypophysitis in patients with metastatic melanoma and renal cancer," Journal of Immunotherapy, vol. 28, no. 6, pp. 593-598, 2005.

[106] M. Gavin and A. Rudensky, "Control of immune homeostasis by naturally arising regulatory $\mathrm{CD}^{+} \mathrm{T}$ cells," Current Opinion in Immunology, vol. 15, no. 6, pp. 690-696, 2003.

[107] S. Sakaguchi, "Naturally arising Foxp3-expressing $\mathrm{CD} 25^{+} \mathrm{CD} 4^{+}$regulatory $\mathrm{T}$ cells in immunological tolerance to self and non-self," Nature Immunology, vol. 6, no. 4, pp. 345-352, 2005.

[108] E. Y. Woo, C. S. Chu, T. J. Goletz, et al., "Regulatory $\mathrm{CD} 4{ }^{+} \mathrm{CD} 25^{+} \mathrm{T}$ cells in tumors from patients with early-stage non-small cell lung cancer and late-stage ovarian cancer," Cancer Research, vol. 61, no. 12, pp. 4766-4772, 2001.

[109] A. M. Wolf, D. Wolf, M. Steurer, G. Gastl, E. Gunsilius, and B. Grubeck-Loebenstein, "Increase of regulatory T cells in the peripheral blood of cancer patients," Clinical Cancer Research, vol. 9, no. 2, pp. 606-612, 2003.

[110] S. Onizuka, I. Tawara, J. Shimizu, S. Sakaguchi, T. Fujita, and E. Nakayama, "Tumor rejection by in vivo administration of anti-CD25 (interleukin-2 receptor $\alpha$ ) monoclonal antibody," Cancer Research, vol. 59, no. 13, pp. 3128-3133, 1999.

[111] J. Shimizu, S. Yamazaki, and S. Sakaguchi, "Induction of tumor immunity by removing $\mathrm{CD} 25^{+} \mathrm{CD} 4^{+} \mathrm{T}$ cells: a common basis between tumor immunity and autoimmunity," Journal of Immunology, vol. 163, no. 10, pp. 5211-5218, 1999.

[112] C. Kudo-Saito, J. Schlom, K. Camphausen, C. N. Coleman, and J. W. Hodge, "The requirement of multimodal therapy (vaccine, local tumor radiation, and reduction of suppressor cells) to eliminate established tumors," Clinical Cancer Research, vol. 11, no. 12, pp. 4533-4544, 2005.
[113] M. T. Litzinger, R. Fernando, T. J. Curiel, D. W. Grosenbach, J. Schlom, and C. Palena, "IL-2 immunotoxin denileukin diftitox reduces regulatory $\mathrm{T}$ cells and enhances vaccinemediated T-cell immunity," Blood, vol. 110, no. 9, pp. 31923201, 2007.

[114] B. Barnett, I. Kryczek, P. Cheng, W. Zou, and T. J. Curiel, "Regulatory T cells in ovarian cancer: biology and therapeutic potential," American Journal of Reproductive Immunology, vol. 54, no. 6, pp. 369-377, 2005.

[115] K. Mahnke, K. Schonfeld, S. Fondel, et al., "Depletion of $\mathrm{CD} 4^{+} \mathrm{CD} 25^{+}$human regulatory $\mathrm{T}$ cells in vivo: kinetics of Treg depletion and alterations in immune functions in vivo and in vitro," International Journal of Cancer, vol. 120, no. 12, pp. 2723-2733, 2007.

[116] M. A. Morse, A. C. Hobeika, T. Osada, et al., "Depletion of human regulatory $\mathrm{T}$ cells specifically enhances antigenspecific immune responses to cancer vaccines," Blood, vol. 112, no. 3, pp. 610-618, 2008.

[117] J. Dannull, Z. Su, D. Rizzieri, et al., "Enhancement of vaccine-mediated antitumor immunity in cancer patients after depletion of regulatory T cells," Journal of Clinical Investigation, vol. 115, no. 12, pp. 3623-3633, 2005.

[118] G. C. Blobe, W. P. Schiemann, and H. F. Lodish, "Role of transforming growth factor $\beta$ in human disease," The New England Journal of Medicine, vol. 342, no. 18, pp. 1350-1358, 2000.

[119] B. A. Teicher, "Malignant cells, directors of the malignant process: role of transforming growth factor-beta," Cancer and Metastasis Reviews, vol. 20, no. 1-2, pp. 133-143, 2001.

[120] S. H. Wrzesinski, Y. Y. Wan, and R. A. Flavell, "Transforming growth factor- $\beta$ and the immune response: implications for anticancer therapy," Clinical Cancer Research, vol. 13, no. 18, part 1, pp. 5262-5270, 2007.

[121] M. G. di Bari, M. E. Lutsiak, S. Takai, et al., "TGF-beta modulates the functionality of tumor-infiltrating $\mathrm{CD}^{+} \mathrm{T}$ cells through effects on TCR signaling and Spred1 expression," Cancer Immunology, Immunotherapy, vol. 58, no. 11, pp. 1809-1818, 2009.

[122] M. Terabe, E. Ambrosino, S. Takaku, et al., "Synergistic enhancement of $\mathrm{CD}^{+} \mathrm{T}$ cell-mediated tumor vaccine efficacy by an anti-transforming growth factor- $\beta$ monoclonal antibody," Clinical Cancer Research, vol. 15, no. 21, pp. 65606569, 2009.

[123] J. Folkman, "Angiogenesis in cancer, vascular, rheumatoid and other disease," Nature Medicine, vol. 1, no. 1, pp. 27-31, 1995.

[124] K. J. Kim, B. Li, J. Winer, et al., "Inhibition of vascular endothelial growth factor-induced angiogenesis suppresses tumour growth in vivo," Nature, vol. 362, no. 6423, pp. 841844, 1993.

[125] P. Allavena, A. Sica, C. Garlanda, and A. Mantovani, "The Yin-Yang of tumor-associated macrophages in neoplastic progression and immune surveillance," Immunological Reviews, vol. 222, no. 1, pp. 155-161, 2008.

[126] D. I. Gabrilovich, T. Ishida, S. Nadaf, J. E. Ohm, and D. P. Carbone, "Antibodies to vascular endothelial growth factor enhance the efficacy of cancer immunotherapy by improving endogenous dendritic cell function," Clinical Cancer Research, vol. 5, no. 10, pp. 2963-2970, 1999. 


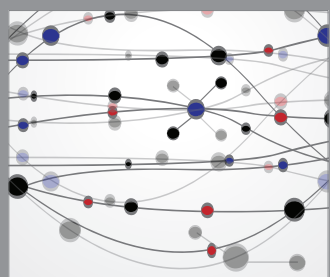

The Scientific World Journal
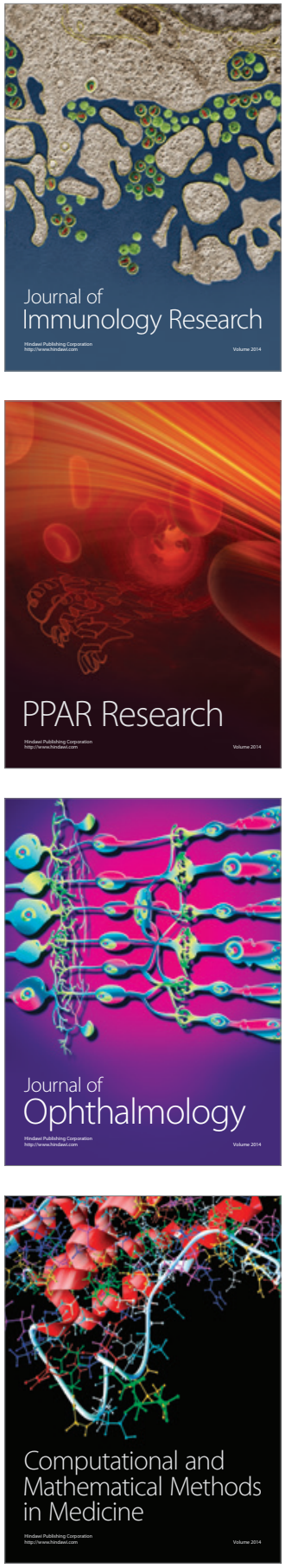

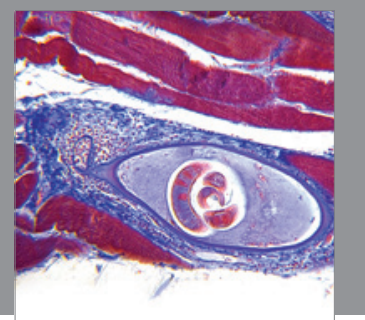

Gastroenterology

Research and Practice
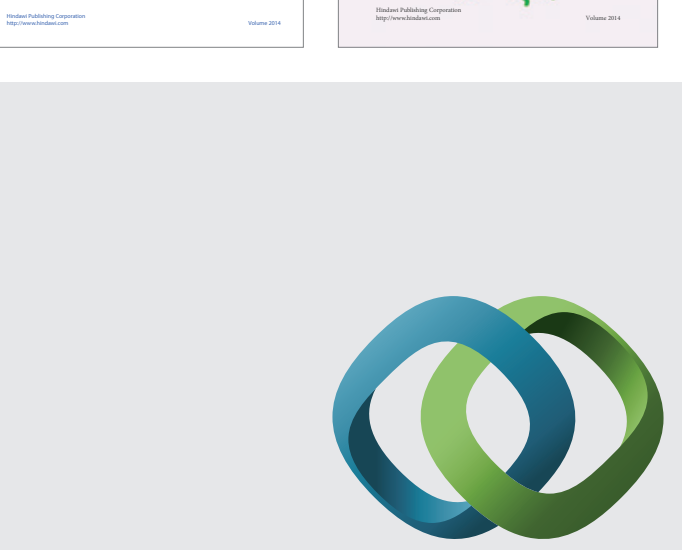

\section{Hindawi}

Submit your manuscripts at

http://www.hindawi.com
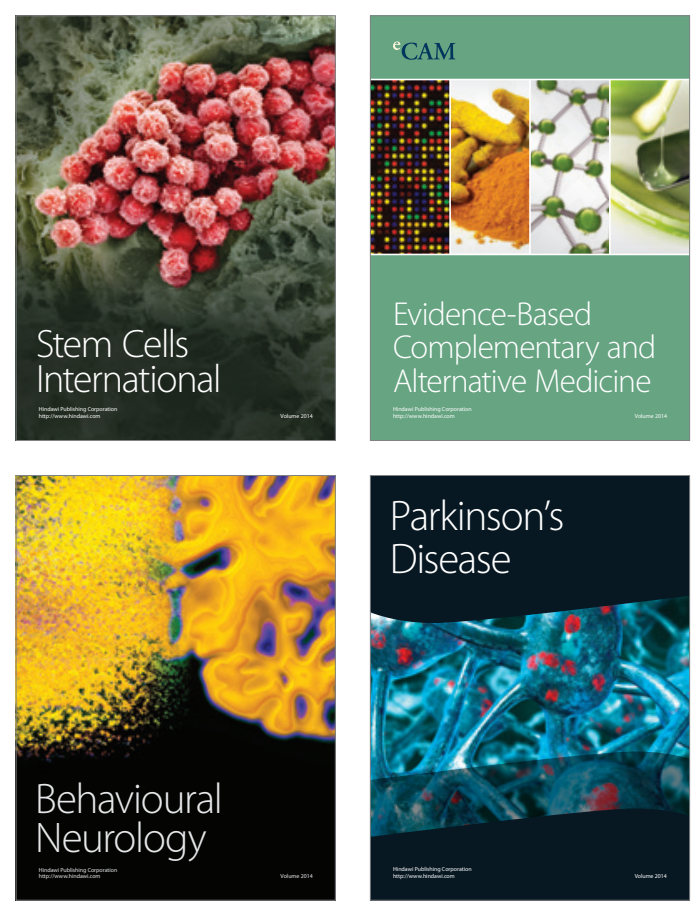

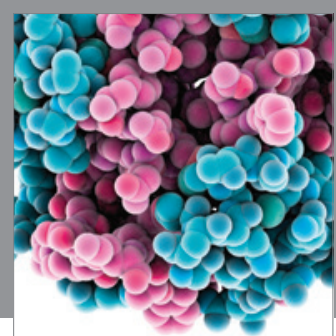

Journal of
Diabetes Research

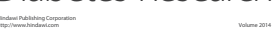

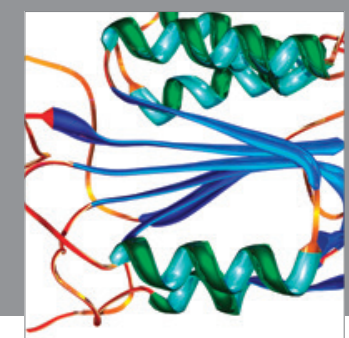

Disease Markers
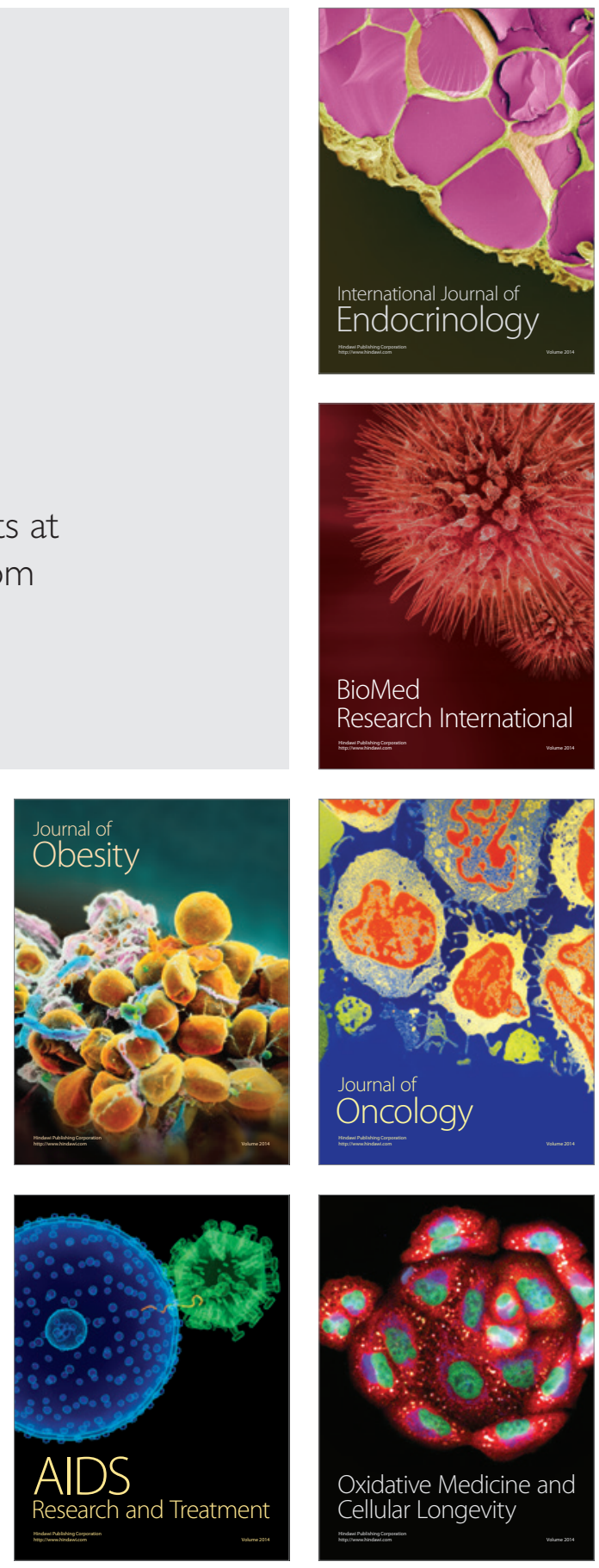